\title{
Pharmaceutical Quality by Design: Product and Process Development, Understanding, and Control
}

\author{
Lawrence $X$. Yu ${ }^{1,2}$
}

Erratum to: Pharmaceutical Research

DOI 10.1007/s11095-007-9511-1

The article was published with an incorrect e-mail address for the corresponding author. The correct e-mail address appears below in footnote 2 .

\footnotetext{
${ }^{1}$ Food and Drug Administration, Office of Generic Drugs, 7519 Standish Place, Rockville, MD 20855, USA.

${ }^{2}$ To whom correspondence should be addressed. (e-mail: Lawrence.Yu@fda.hhs.gov)
}

The online version of the original article can be found at: http://dx.doi.org/10.1007/s11095-007-9511-1. 